\title{
Effect of Applying A training Program about International Patient Safety Goals on Patient's Safety Culture
}

\author{
Bassam Abduh Saaid ${ }^{1}$, Samah Mohammed Abdalla ${ }^{2}$, Nahed Shawkat Abo Elmagd ${ }^{3}$. \\ 1. Assistant Lecturer of Nursing Administration, Faculty of Medicine and Health Science Hodiedah University, \\ Yemen. \\ 2. Prof. of Nursing Administration Department, Faculty of Nursing, Assiut University, Egypt. \\ 3. Assistant Prof. of Nursing Administration Department, Faculty of Nursing, Assiut University, Egypt.
}

\begin{abstract}
s
Background: The goal of head nurses is to achieve patient safety, which is considered a critical component of quality health care. Aim: To assess the effect of applying a training program about international patient safety goals on patient's safety culture at Rajhy Liver Hospital, Assiut University. Subject and method: A quasi-experimental design used to conduct this study. The study subjects included all head nurses $(n=29)$ from different health care units. The data collection tool included three tools: I. Personal data questionnaire, II. Head nurses management regarding patient's safety questionnaire, and III. Hospital survey on patient's safety culture questionnaire. Results: there was a highly statistically significant difference with a strong positive correlation impact between head nurses' management regarding applying international patient safety goals using the PDCA model and patient's safety culture. Conclusion: The implementation of a training program is successful and effective in improving head nurses' management regarding applying international patient safety goals using the PDCA model after implementing the training program. Recommendations: The continuous training program and development activities about international patient safety goals should be applied to all head and staff nurses in the study setting, and extended to other similar settings.
\end{abstract}

\section{Keywords: Patient Safety Goals, Patient's Safety Culture \& Training Program.}

\section{Introduction}

Nowadays, patient safety is a new healthcare issue in the healthcare organizations that includes reducing and preventing medical fault that often leads to harmful health consequences. Health care has become more efficient and also become more complex, with greater application of new technologies and therapies, which needs adopting with the international patient safety goals to improve the patient safety environment to simulate international competition and to increase the competitive advantages of the healthcare organizations at the national and international grades. (Abousallah, 2018)

World Health Organization (WHO, 2016) defines patient safety as the prevention of errors and adverse effects to the patient associated with health care and to not harm patients (Kuriakose et al., 2020). The Joint Commission International (JCI, 2011), published international patient safety goals that can be used to assess head nurses' management, aims to decrease errors resulting from healthcare in care environments. Its six goals are: (a) Identifying patients correctly; (b) Improving effective communication; (c) Maintaining the safety of highalert medications; (d) Ensuring correct procedure; (e) Reducing the risk of healthcare-associated infections; (f) Reducing the risk of patient harm resulting from falls. (Aguiar et al., 2017)

Hospital administrators, specifically head nurses, should conform to the standard practices concerning patient safety. It is also worth assessing whether head nurses have perceived the patient safety goal statements appropriately. Furthermore, head nurses must have the competency to design, communicate, and apply these patient safety goals to all nurses and other healthcare providers under their supervision. In order, to apply patient safety goals in the unit, head nurses need a tool/method to guide the effective implementation of these goals. (Yuswardi, et al., 2015)

The most common method applying in healthcare for patient safety management is the PDCA (plan-docheck-act) cycle or the Deming model. The PDCA model consists of (a) plan, identifying, establishing informed goals, setting guidelines, and analyzing the problems, establishing objectives, and how they will be achieved. (b) do, implementing the plan, emphasizing responsibility, explaining instruction and encouraging staff, (c) check, analyzing results, monitoring staff, implementing audit programs, and modifying the plan to realize implementation. (d) act, introducing systemic changes, evaluating the program, supervising staff, 
revising the program, and training the staff. Each will be further elaborated upon about the head nurses management of patient safety. (Boonyoung et al., 2013)

Patient safety culture is defined as an integrated pattern of individual and organizational behavior, based upon shared beliefs and values that continuously seek to minimize patient harm, which may result from the processes of care delivery (Nordin, 2015). The evaluation of the patient safety culture is the first step in establishing a culture that promotes and supports safety. (Mahrous, 2018). According to the Agency for Healthcare Research and Quality (AHRQ), the Hospital Survey on Patient Safety Culture (HSOPSC), there are twelve dimensions of patient safety culture (Gunawan \& Hariyati, 2019)

Patient safety culture is divided into three aspects: (a) patient safety culture at unit-level aspects that include; supervisor/manager expectations \& actions promoting safety, organizational learningcontinuous improvement, teamwork within units, communication openness, feedback, and communication about the error and non-punitive response to error and staffing. (b) patient safety culture at hospital-level aspects that include; hospital management support for patient safety, teamwork across units, and hospital handoffs and transitions. (c) patient safety culture at outcome-level aspects that include; overall perceptions of safety and frequency of event reporting. (Ammouri et al., 2015)

Hospitals must provide quality service by creating a safe, effective, and well-managed hospital organization. One of the key activities is the evaluation of the patient safety culture in nursing practice at the hospitals. (Gunawan \& Hariyati, 2019). The implementation of the training program would lead to improvements in the knowledge and practice of the head and staff nurses' application in patient safety goals using PDCA. The application of the PDCA cycle more effective than adopting the right-first-time approach. Using the PDCA cycle means continuously looking for better methods of improvement. The PDCA cycle is effective in doing a job and managing a program. (Seliem et al., 2019)

\section{Significance of the study}

Many researchers indicated that patient safety is a global public health problem, but only a few were oriented to the relation between the applying of international safety goals and patient safety culture. In contrast, no study was applied to investigate this relation in Egypt. Internationally, Abousallah, (2018), showed the applying of international safety goals has a vast impact on most hospital's services with a strong positive effect on the patient safety culture. Also, Yuswardi et al., (2015), recommended that, conduct the training program for head nurses to improve their skill in managing patient safety. Nationally, Mady et al., (2017), recommended that the importance of continuoustraining programs and evaluation for nurses about application the international safety goals. Also, Seliem et al., (2019), recommended that the training program should be applied to all head and staff nurses in the study setting, and should be extended to other similar settings. Finally, the results of this study will be useful to improve patient safety management, especially at Rajhy Liver HospitalAssiut University.

Aims of the study

The current study aims to assess the effect of applying a training program about international patient safety goals on patient's safety culture at Rajhy Liver Hospital-Assiut University, through:

1. Assess the level of head nurses' management regarding patient's safety using the PDCA model at Rajhy Liver Hospital-Assiut University.

2. Assess the level of head nurses' perceptions regarding patient $\mathrm{s}$ safety culture at Rajhy Liver Hospital-Assiut University.

3. Developing a training program about applying international patient safety goals using the PDCA model for head nurses at Rajhy Liver Hospital-Assiut University.

\section{Study hypotheses}

To fulfill the aim of the study, the following research hypotheses were formulated:

1. Hypothesis (H.1): There is a high mean score level of head nurses management regarding patient safety using the PDCA model after the training program is implemented.

2. Hypothesis (H.2): There is a high mean score level of head nurses' perceptions regarding patient's safety culture after the training program is implemented.

1. Hypothesis (H.3): There is a highly significant positive impact after applying a training program about international patient safety goals using the PDCA model on patient's safety culture for head nurses.

\section{Subjects and methods}

The methodology followed in carrying out the study is presented in four designs, namely: technical, operational, administrative, and statistical design.

\section{Technical design}

This design involved the study design, setting, subject, and tools of data collection. 


\section{Study design}

A quasi-experimental design with a pre-post assessment was utilized for this study.

\section{Study setting}

The study was conducted at Rajhy Liver HospitalAssiut University in all health care units $(n=12)$ included; Medical unit, Surgical unit, Operating room unit, Liver care unit (LCU), Intensive care unit (ICU), Critical care unit (CCU), Interventional and $\mathrm{X}$-ray radiology, Infection control unit, Endemic unit, Endoscopes unit, Outpatient clinics unit, and Laboratory unit.

\section{Study Subjects}

The study subjects included all head nurses $(n=29)$ from different health care units at Rajhy Liver Hospital-Assiut University.

\section{Tools of the study}

The study tools were used for data collection. It consisted of three tools:

* First tool: Personal Data Questionnaire (PDQ); this questionnaire was developed by the researcher. It is used to gather data about head nurses regarding personal datasheet as a unit (workplace), age, gender, level of education, years of experience, and type of nursing care delivery.

* Second tool: Head Nurses Management regarding Patient's Safety questionnaire (HNM-PSQ); this questionnaire was developed by Yuswardi et al., (2015), to assess levels of head nurses' management regarding patient's safety and displaying the use of the PDCA cycle. The PDCA method stands for Plan, Do, Check, and Act. Also, the PDCA method is used to measure each item of patient safety goals statements. The total items consist of (83) items; identifying patients correctly (12 items), improving effective communication (12 items), maintaining the safety of high alert medications (14 items), ensuring correct procedure (12 items), reducing the risk of healthcare-associated infections (19 items), and reducing the risk from fall (14 items).

\section{Scoring system}

Each statement is rated on a five-point Likert scale, the scores ranging from value 1 (like or do not perform) to value 5 (exactly perform) are used throughout the questionnaire, as follows: Head nurse performed patient safety management $(1=\operatorname{did}$ not perform, $2=$ less perform, $3=$ moderate perform, $4=$ much likely perform, $5=$ exactly perform). The total scores of patient safety goals statements were calculated and presented as the average scores and classified into; high, moderate, and low.
* Third tool: Hospital Survey on Patient's Safety Culture (HISOPSC) questionnaire; this questionnaire was developed by Abousallah (2018), to assess the levels of head nurses' perceptions regarding patient's safety culture. It is included (12) patient's safety culture dimensions as (7) patient safety culture at Unit-level aspects, included; supervisor/manager expectations \&actions promoting safety, organizational learningcontinuous improvement, teamwork within units, communication openness, feedback and communication about the error, non-punitive response to error, and staffing, and (3) patient safety culture at hospital-level aspect included; hospital management support for patient safety, teamwork across units, and hospital handoffs and transitions and (2) patient safety culture at outcome-level aspects included; overall perceptions of safety, and frequency of event reporting. Each sub-dimension is measured by 3-4 items. The total items consist of (42) items.

\section{Scoring system}

Each statement is rated on a five-point Likert scale; the scores ranging from value 1 (strongly disagree) to value 5 (strongly agree) are used throughout the questionnaire as follows: (1=strongly disagree, $2=$ disagree, $3=$ neither agree nor non-disagree, $4=$ agree, $5=$ strongly agree). The total scores of the patient safety culture dimensions were calculated and presented as dimensions with positive response rates of (75\% or above) will be identified as strengths. Dimensions with positive response rates of (at least $50 \%$ ) will be identified as potential for improvement, and dimensions with positive response rates of (less than 50\%) will be identified as weaknesses.

Operational design

This design explains the steps of the actual implementation of the study, including the pilot and fieldwork.

Pilot study

A pilot study was carried out on a group (10\%) of the study subjects chosen randomly in different hospital departments to ensure the clarity, reliability, accessibility, time-consuming, and understanding of the study tools before the beginning of actual data collection. The content validity of the training program and Arabic translation of the study tools were reviewed by the expertise of the nursing administration department (Jury from five experts in the specialty). The study tools reliability tested using (a) Cronbach's test for the structured questionnaires as 0.947 for Head Nurses Management regarding Patient's Safety questionnaire (HNM-PSQ) and 
0.955 for Hospital Survey on Patient's Safety Culture (HISOPSC) questionnaire.

\section{Fieldwork}

The researcher started to collect data and implement the training program from the $4^{\text {th }}$ week, August, and lasted at $2^{\text {nd }}$ week from September (2019) and follow-up after 3 months later. The researcher develops a training program through four phases:

The assessment phase of a training program: The data was collected during this phase constituted the pre-test or baseline for the study.

The planning phase of a training program: The program was planned and designed based on the needs assessment in this study through (pre-test questionnaire). The training program was conducted in the measurement and evaluation unit at the Faculty of Nursing- Assiut University.

The implementation phase of a training program: The program was implemented by the researcher and the supervisors of the thesis on the representative participants from head nurses $(n=27)$ from different units/departments at Rajhy Liver Hospital-Assiut University. The participants were divided into three groups. Every group consist $(n=9)$ participant. The groups organized to avoid shortage and don't distributed their work in the units-the program implemented in three days for each group. The course content was spread into nine sessions for every group. The total time of the program was 40.5 hours, three sessions per day, every session 1.5 hours for the three groups. At the beginning of the first session, an orientation to the program, and its purpose was done, and the participants were informed about the time and place of the session taken. The teaching methods used of the program included; lectures, small group discussions, group discussion brainstorming, demonstration, case study, practical training. Teaching aids used included; Handbook published by General Authority for Egyptian National Library and Archives, Deposit Number (13150/2020), handout, PowerPoint, flip charts, photographs and drawings for illustrations, models (Id wrist bands), and video presentation.

The evaluation phase of a training program: Immediately after implementation of the training program, the researcher use post-test format to evaluate the effect of the training program as same pre-test format that was used at the beginning of program implementation, after three months later for the follow-up to evaluate the retention of head nurses management regarding applying of international patient safety goals using PDCA model.

\section{Administrative design}

Official permission to collect data and implement a training program was obtained from the Dean of
Faculty of Nursing-Assiut University, Hospital director, and Nursing Director of Rajhy Liver Hospital-Assiut University.

\section{Ethical considerations}

The research proposal was approved by the Ethical Committee in the Faculty of Nursing. The study was to follow common ethical principles in research. The study subjects had the right to refuse to participate and /or withdraw from the study at any time. There was no risk for study subjects during the application of the research. Study subjects' privacy was considered during the collection of data. The purpose of this study was explained to all participants. Informed them that the information and data obtained would be confidential and used only for the purpose of the study - oral and written consent taken from the participants through document dating before the training program was implemented.

Limitations of the study

Withdraw for (2) of head nurses after participated in the pre-test phase without presenting the program.

\section{Statistical design}

Collected data were verified prior to computerized data entry and analysis by using a statistical software package for social sciences (IBM SPSS-22). Data were presented using descriptive statistics in the form frequencies and percentages. Quantitative variables were presented in the form of means and standard deviation. Qualitative variables were compared using (chi-square test) and (ANOVA test). Used (Person Correlation) to examine the association between scores was considered a statistical significance difference $(\mathrm{P}<0.05)$. 


\section{Results}

Table (1): Percentage distribution of head nurses personal data participated in the training program at Rajhy Liver Hospital - Assiut University (N=27).

\begin{tabular}{|c|c|c|c|}
\hline \multirow{2}{*}{\multicolumn{2}{|c|}{ Variables }} & \multicolumn{2}{|c|}{ No. $=27$} \\
\hline & & No & $\%$ \\
\hline 1. & Age & & \\
\hline$\bullet$ & $<25$ year & 2 & 7.4 \\
\hline$\bullet$ & $25-<35$ year & 20 & 74.1 \\
\hline$\bullet$ & $35-<45$ year & 4 & 14.8 \\
\hline$\bullet$ & $>45$ year & 1 & 3.7 \\
\hline 2. & Gender & & \\
\hline$\bullet$ & Male & 1 & 3.7 \\
\hline$\bullet$ & Female & 26 & 96.3 \\
\hline 3. & Work unit place & & \\
\hline$\bullet$ & Medical (Gastroenterology) unit & 3 & 11.1 \\
\hline$\bullet$ & Surgical (Liver and Gastroenterology) unit & 2 & 7.4 \\
\hline$\bullet$ & Intensive care unit (ICU) & 2 & 7.4 \\
\hline$\bullet$ & Critical care unit (CCU) & 2 & 7.4 \\
\hline$\bullet$ & Liver care unit (LCU) & 3 & 11.1 \\
\hline$\bullet$ & Operating room unit & 4 & 14.8 \\
\hline$\bullet$ & Endemic unit & 2 & 7.4 \\
\hline$\bullet$ & Endoscopes unit & 2 & 7.4 \\
\hline$\bullet$ & Outpatient clinics unit & 1 & 3.7 \\
\hline$\bullet$ & Interventional and X-ray radiology & 2 & 7.4 \\
\hline$\bullet$ & Laboratory unit & 1 & 3.7 \\
\hline$\bullet$ & Control infection unit & 2 & 7.4 \\
\hline$\bullet$ & Nursing director office & 1 & 3.7 \\
\hline 4. & Level of education & & \\
\hline$\bullet$ & Bachelor of Nursing & 22 & 81.5 \\
\hline$\bullet$ & Master's of Nursing & 4 & 14.8 \\
\hline$\bullet$ & Doctorate of Nursing & 1 & 3.7 \\
\hline 5. & Years of experience & & \\
\hline$\bullet$ & $<5$ year & 11 & 40.7 \\
\hline$\bullet$ & $5-<10$ year & 8 & 29.6 \\
\hline$\bullet$ & $10-<15$ year & 5 & 18.5 \\
\hline$\bullet$ & $>15$ year & 3 & 11.1 \\
\hline 6. & Type of nursing care delivery method & & \\
\hline$\bullet$ & Total patient care (Case method) & 20 & 74.1 \\
\hline$\bullet$ & Functional care (Task method) & 2 & 7.4 \\
\hline$\bullet$ & Team care method & 5 & 18.5 \\
\hline
\end{tabular}

Table (2): Total mean score of head nurses management regarding applying international patient safety goals (IPSG) using (PDCA) model during the different periods of the testing training program $(\mathrm{N}=27)$

\begin{tabular}{|c|c|c|c|c|}
\hline \multirow{2}{*}{$\begin{array}{l}\text { Head nurses Management } \\
\text { regarding applying (IPSG) using (PDCA) model }\end{array}$} & Pre & Post & $\begin{array}{l}\text { Follow-up } \\
3 \text { months }\end{array}$ & \multirow{2}{*}{$\begin{array}{c}P . \\
\text { value }\end{array}$} \\
\hline & \multicolumn{3}{|c|}{ Mean \pm SD } & \\
\hline - IPSG(1):Patient identification & $28.44 \pm 6.01$ & $54.59 \pm 3.63$ & $53.37 \pm 4.84$ & $<0.001 * *$ \\
\hline - IPSG(2):Effective communication & $26.74 \pm 4.91$ & $53.11 \pm 4.26$ & $52 \pm 5.24$ & $<0.001 * *$ \\
\hline - IPSG(3):High alert medications & $33.85 \pm 5.56$ & $64.33 \pm 4.77$ & $61.41 \pm 7.6$ & $<0.001 * *$ \\
\hline - IPSG(4):Correct surgery procedure & $28.59 \pm 5.97$ & $55.26 \pm 4.4$ & $53.26 \pm 6.1$ & $<0.001 * *$ \\
\hline - IPSG(5):Risk of health care associated infection & $47.89 \pm 10.87$ & $86.93 \pm 7.63$ & $84.33 \pm 9.27$ & $<0.001 * *$ \\
\hline $\begin{array}{ll} & \text { IPSG(6):Risk from patient fall } \\
\end{array}$ & $32.15 \pm 6.43$ & $60.37 \pm 7.7$ & $58.63 \pm 8.62$ & $<0.001 * *$ \\
\hline Total score & $197.67 \pm 33.39$ & $374.59 \pm 26.92$ & $363 \pm 36.75$ & $<0.001 * *$ \\
\hline
\end{tabular}

*statistically significant differences 


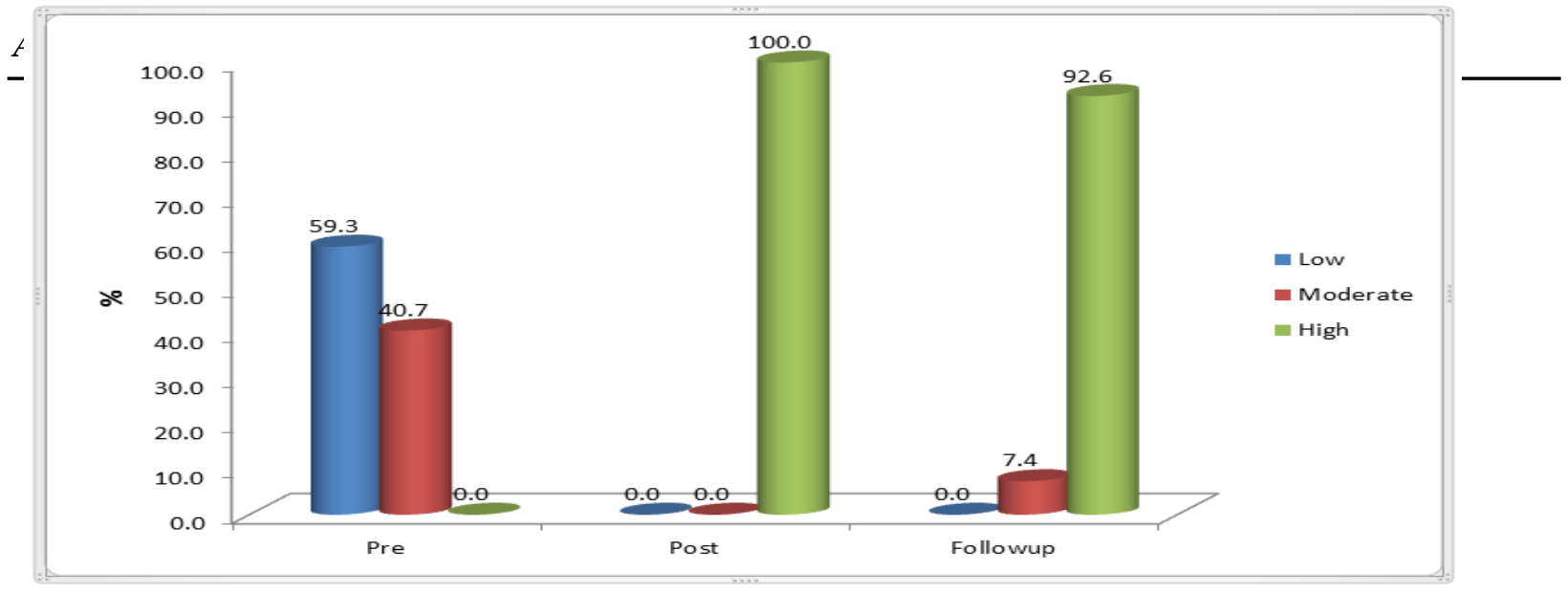

Figure (1): Percentage distribution of head nurses management level regarding improving effective communication using (PDCA) model during the different periods of the testing training program $(\mathrm{N}=27)$

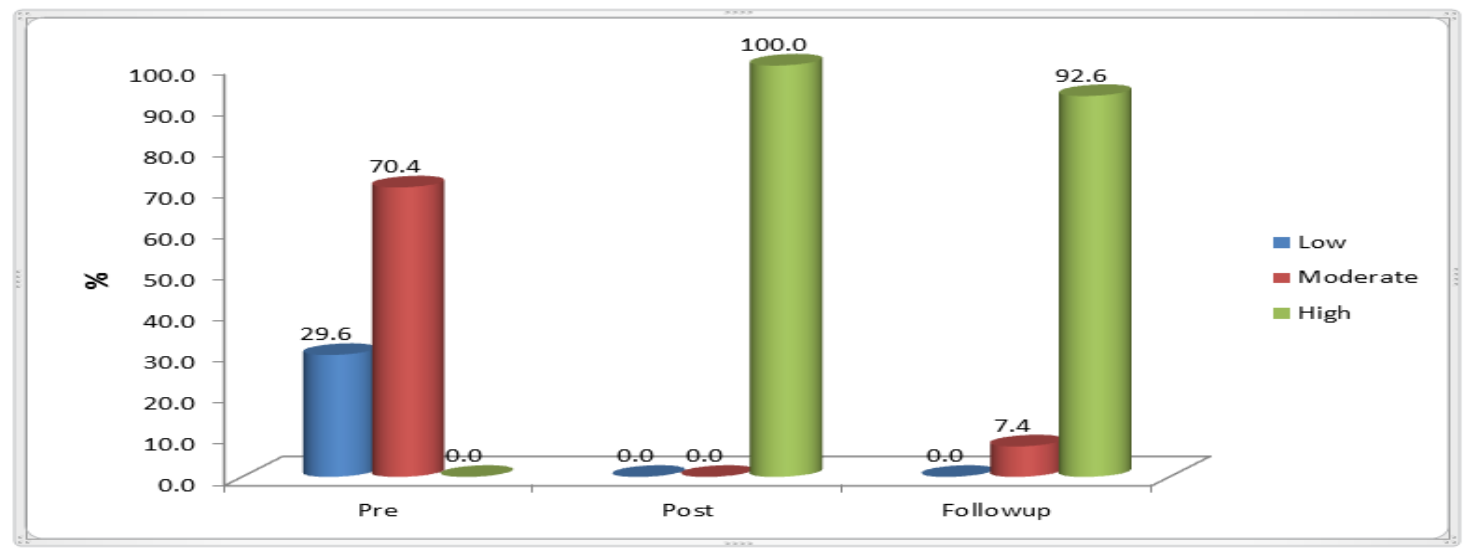

Figure (2): Percentage distribution of head nurses management level regarding reducing the risk of patient fall using (PDCA) model during the different periods of the testing training program $(\mathrm{N}=27)$

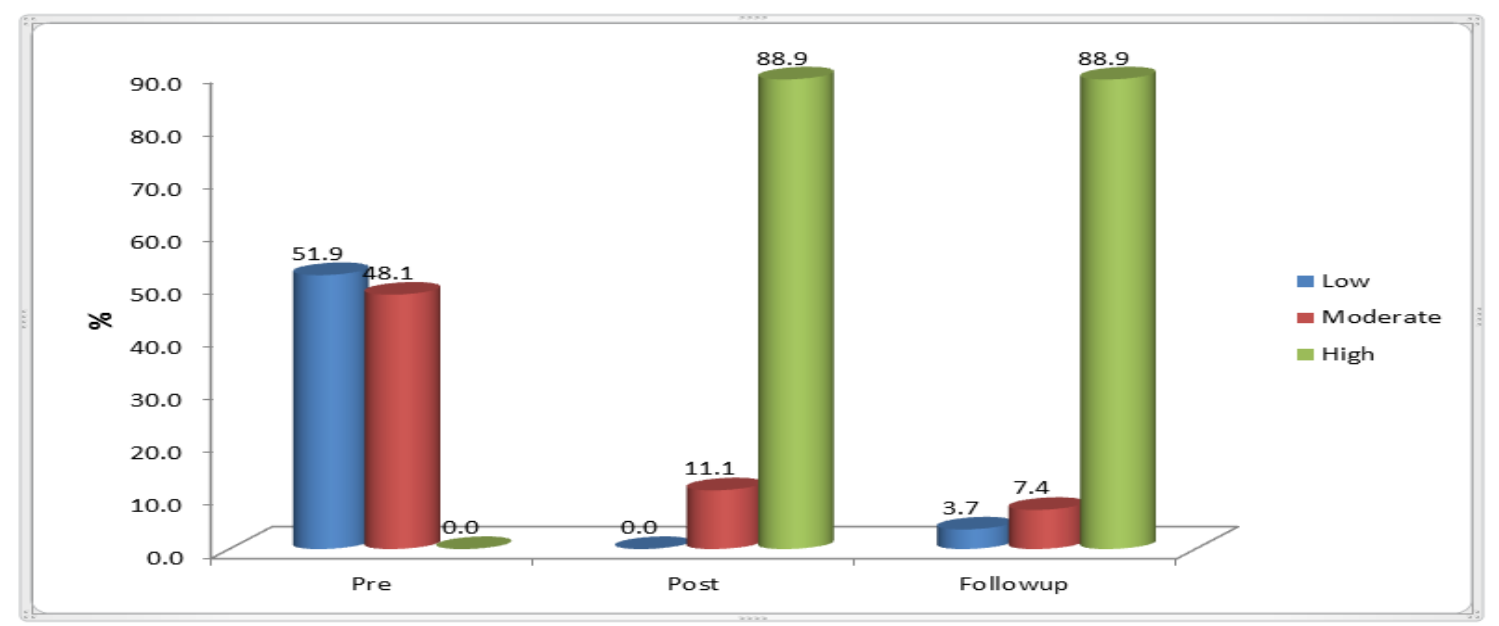

Figure (3): Percentage distribution of head nurses management level regarding applying international patient safety goals (IPSG) using (PDCA) model during the different periods of the testing training program (N=27). 
Table (3): Total mean score of head nurses perception regarding patient's safety culture (PSC) aspects during the different periods of the testing training program $(\mathrm{N}=27)$

\begin{tabular}{|c|c|c|c|c|}
\hline \multirow{2}{*}{$\begin{array}{l}\text { Patient safety culture (PSC) } \\
\text { aspects }\end{array}$} & Pre & Post & $\begin{array}{c}\text { Follow-up } \\
3 \text { months }\end{array}$ & \multirow{2}{*}{$\begin{array}{c}\text { P. } \\
\text { value }\end{array}$} \\
\hline & \multicolumn{3}{|c|}{ Mean \pm SD } & \\
\hline Patient's safety culture at unit -level aspects & $73.59 \pm 12.19$ & $99.48 \pm 16.12$ & $97.52 \pm 10.93$ & $<0.001 * *$ \\
\hline - Supervisor expectations promoting safety & $12.44 \pm 3.02$ & $16.52 \pm 2.68$ & $16.41 \pm 1.95$ & $<0.001 * *$ \\
\hline - Organizational-learning-continuous improvement & $12.26 \pm 2.81$ & $16.48 \pm 3.47$ & $16.7 \pm 2.11$ & $<0.001 * *$ \\
\hline • Teamwork within units & $9.59 \pm 1.5$ & $12.96 \pm 2.7$ & $12.56 \pm 1.8$ & $<0.001 * *$ \\
\hline - Communication openness & $9.44 \pm 2.03$ & $12.41 \pm 2.44$ & $11.81 \pm 2.22$ & $<0.001 * *$ \\
\hline - Feedback- \&communication about error & $9.63 \pm 1.39$ & $12.81 \pm 2.73$ & $12.89 \pm 1.63$ & $<0.001 * *$ \\
\hline - Non-punitive response to error & $9.52 \pm 1.85$ & $12.93 \pm 2.04$ & $12.37 \pm 2.4$ & $<0.001 * *$ \\
\hline - Staffing & $10.7 \pm 2.83$ & $15.37 \pm 2.9$ & $14.78 \pm 3.15$ & $<0.001 * *$ \\
\hline Patient's safety culture at hospital -level aspects & $31.85 \pm 5.3$ & $43.37 \pm 5.91$ & $43.41 \pm 4.09$ & $<0.001 * *$ \\
\hline - Hospital-management support for patient safety & $9.37 \pm 1.92$ & $12.44 \pm 2.45$ & $12.48 \pm 1.34$ & $<0.001 * *$ \\
\hline - Teamwork across units & $11.89 \pm 2.21$ & $16.04 \pm 2.92$ & $15.81 \pm 1.92$ & $<0.001 * *$ \\
\hline - Hospital handoffs \&transitions & $10.59 \pm 2.59$ & $14.89 \pm 1.8$ & $15.11 \pm 2.71$ & $<0.001 * *$ \\
\hline Patient's safety at outcome-level aspects & $20 \pm 3.86$ & $30.22 \pm 3.66$ & $26.85 \pm 4.35$ & $<0.001 * *$ \\
\hline - Overall perceptions of safety & $11.26 \pm 2.14$ & $17.11 \pm 2.61$ & $15.52 \pm 2.62$ & $<0.001 * *$ \\
\hline - Frequency of event reporting & $8.74 \pm 2.01$ & $13.11 \pm 1.53$ & $11.33 \pm 1.92$ & $<0.001 * *$ \\
\hline Total score & $125.44 \pm 18.74$ & $173.07 \pm 24.15$ & $167.78 \pm 16.06$ & $<0.001 * *$ \\
\hline
\end{tabular}

*statistically significant differences

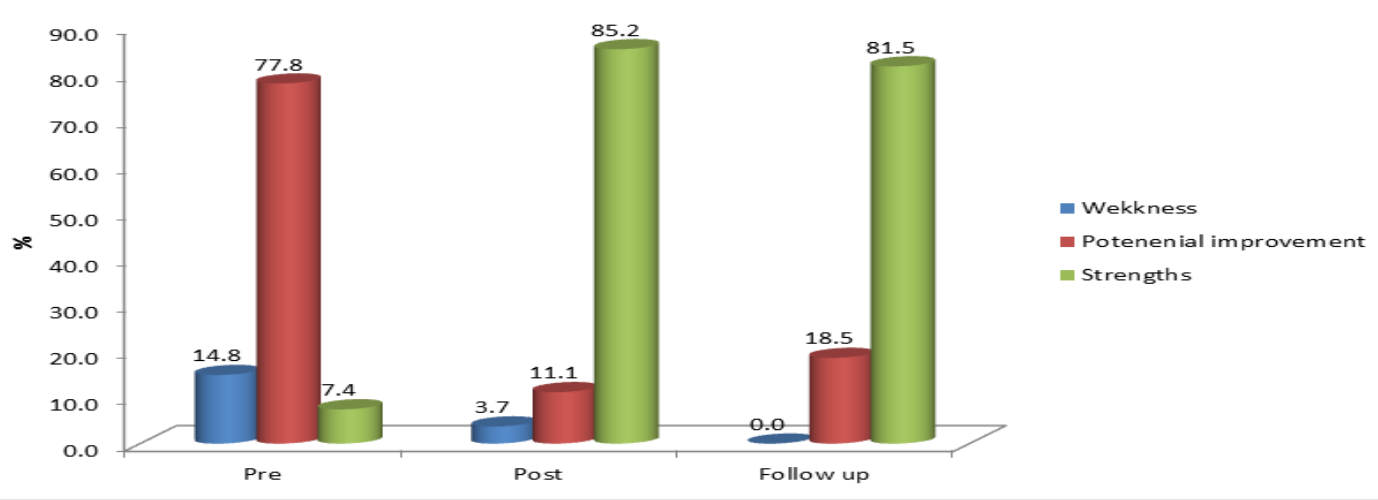

Figure (4): Percentage distribution of head nurses perception level regarding patient's safety culture (PSC) aspects during the different periods of the testing training program $(N=27)$

Table (4): Correlation between head nurses management regarding international patient safety goals (IPSG) and patient safety culture during the different periods of the testing training program $(\mathrm{N}=27)$

\begin{tabular}{|c|c|c|c|c|c|c|}
\hline \multirow{3}{*}{$\begin{array}{l}\text { International Patient } \\
\text { Safety Goals } \\
\text { (IPSG) }\end{array}$} & \multicolumn{6}{|c|}{ Patient Safety Culture (PSC) } \\
\hline & \multicolumn{2}{|c|}{ Pre } & \multicolumn{2}{|c|}{ Post } & \multicolumn{2}{|c|}{$\begin{array}{c}\text { Follow-up } \\
3 \text { months } \\
\end{array}$} \\
\hline & $\mathbf{r}$ & $\mathbf{p}$ & $\mathbf{r}$ & $\mathbf{P}$ & $\mathbf{r}$ & $\mathbf{p}$ \\
\hline - IPSG(1):Patient identification & .469 & $0.014^{*}$ & 0.187 & 0.350 & .449 & $0.019^{*}$ \\
\hline - IPSG(2):Effective communication & 0.376 & 0.053 & .597 & $0.001^{* * *}$ & 0.380 & 0.051 \\
\hline - IPSG(3):High alert medications & .535 & $0.004^{* *}$ & 0.356 & 0.069 & .467 & $0.014^{*}$ \\
\hline - IPSG(4):Correct surgery procedure & .576 & $0.002^{* *}$ & .410 & $0.034^{*}$ & .388 & $0.045^{*}$ \\
\hline - IPSG(5): Risk of healthcare-associated infection & .532 & $0.004^{* *}$ & .443 & $0.021^{*}$ & .748 & $0.000^{\text {*** }}$ \\
\hline - IPSG(6): Risk from patient fall & .433 & $0.024^{*}$ & 0.278 & 0.160 & .599 & $0.001^{\text {*** }}$ \\
\hline Total Score & .616 & $0.001^{* *}$ & .395 & $0.042^{*}$ & .713 & $0.000^{* * *}$ \\
\hline
\end{tabular}

*statistically significant differences 
Table (1): Shows that the highest percentage of about more than two-thirds of them $(74.1 \%)$ their age ranged from $25-<35$ years old, and the majority of them $(96.3 \%)$ are female. Whereas, one-quarter of them $(14.8 \%)$ are working in the operating room unit (OR), while less than one-quarter of them (11.1\%) are working in the medical (Gastroenterology) unit, and similarly, in the liver care unit (LCU). Also, the highest percentage of them $(81.5 \%)$ are having a bachelor of nursing. Meanwhile, less than half of them $(40.7 \%)$ have less than 5 years' experience of work. Finally, more than two-thirds of them $(74.15 \%)$ are using the total patient care (Case method) of the nursing care delivery.

Meanwhile, Figure (1): Displays that the highest percentage about less than two-thirds of them $(59.3 \%)$ pre-program implementation have low management level regarding improving effective communication using (PDCA) model. While $(100.0 \%)$ of them have improved post-program implementation become a high management level and then slightly decrease to $(92.6 \%)$ of follow-up after 3 months.

Meanwhile, Figure (2): Presents that the highest percentage of about half of them $(51.9 \%)$ preprogram implementation have low management level regarding reducing the risk of patient fall using (PDCA) model. While, $(88.9 \%)$ of them have improved post-program implementation become high management level and similarly, improve percent stilled of follow-up after 3 months.

Overall, Figure (3): Demonstrates that the highest percentage of about more than two-thirds of them $(70.4 \%)$ pre-program implementation have moderate management level regarding applying international patient safety goals (IPSG) using (PDCA) model. Whereas, (100.0\%) of them have improved postprogram implementation become high management level and then slightly, decrease to (92.6\%) of follow-up after 3 months.

Table (3) shows that the total mean score preprogram implementation $(125.44 \pm 18.74)$ and improve post-program implementation $(173.07 \pm 24.15)$ and then slightly decrease to $(167.78 \pm 16.06)$ of follow-up-program after 3 months. Furthermore, there are highly statistical significance differences $(\mathrm{P}=<0.001)$.

Meanwhile, Figure (4): Reveals that the highest percentage of about more than two-thirds of them $(77.8 \%)$ pre-program implementation have potential improvement levels regarding patient's safety culture (PSC) aspects. Whereas, (85.2. \%) of them have improved post-program implementation become strengths level, and then slightly decrease to $(81.5 \%)$ of follow-up after 3 months.
Table (4): Reveals that there are highly statistical significance differences with a strong positive correlation between international patient safety goals (IPSG) and patient safety culture of pre and followup-program implementation $(* * r<0.6>10.0)$. Meanwhile, there are highly statistical significance differences with mild positive correlation in postprogram implementation $(\mathrm{r}<0.2>0.4)$.

\section{Discussion}

Patient safety is a critical component of quality health care. It is a global challenge that requires knowledge and skills in multiple areas, including human factors and systems engineering (Al-Rafay et al., 2018). Head nurses have an important role in understanding and applying the six international patient safety goals to minimized hazards and errors. The goals highlight the problematic area in health care and describe the evidence and expert-based consensus solution to these problems; the goals are structured in the manner as standards, including goal statement and measurable elements for each goal (JCI, 2011). One of the main head nurses roles in nursing administration is to achieve quality, particularly regarding patient safety the Plan-DoCheck-Act (PDCA) model is an effective quality management tool in improving patients outcomes and augmenting the efficiency of the organization to the maximum (Severinsson, 2013, Johnson et al., 2016, Garrett et al., 2017)

Consequently, the current study was aimed to; assess the effect of applying a training program about international patient safety goals on patient's safety culture through assess the level of head nurses management regarding patient's safety using the PDCA model, and their perception regarding patient's safety culture at Rajhy Liver HospitalAssiut University.

In contrast, the present study hypothesized there is a high mean score level of head nurses management regarding patient safety using the PDCA model and a high mean score level regarding patient's safety culture perceptions. There is a highly significant positive of head nurses' management regarding applying international patient safety goals using the PDCA model on patient's safety culture after the training program is implemented.

The present study findings, according to the distribution of head nurses personal data, participated in the training program in the table (1) showed that the majority of them were females. Whereas, more than two-thirds of them were their age ranged from 25 - < 35 years old, and the highest percent of them had a bachelor of nursing, and less than half of them had $<5$ years' experience of work. Finally, more than two-thirds of them were using the total patient 
care (case method) of the nursing care delivery in their units.

These findings are congruent with Hanifi et al., (2018), who revealed that all of the studied nurses were female, and most of them age groups of the experimental groups were between 25-35 years and experience of work in the control groups were less than 5 years. Also, Seliem et al., (2019), who showed that, all studied head nurses were females and most of them had a bachelor of nursing and more than half of them had $<5$ years' experience of work.

In the same line, Boonyoung et al., (2013), who illustrated that majority of studied head nurses were female, and more than half had a bachelor in nursing, and most of them had $<5$ years' experience of work. Also, Abousallah, (2018), who demonstrated that majority of the studied sample were female, and their age was $<35$ years old, and most of them had a bachelor in nursing, and their career's experience ranged from 6-10 years.

According to the head nurses' management regarding applying international patient safety goals using (PDCA) in (table 2). The present study findings showed that the total mean score before program implementation were moderate management level as regards identifying patient correctly, maintaining the safety of high alert medications, ensuring correct surgery procedure, and reducing the risk of healthcare-associated infection using (PDCA) model and were low management level as regards improving effective communication and reducing the risk of patient fall using (PDCA) model.

These present findings were not consistent with Boonyoung et al., (2013), who illustrated that the total mean score before program implementation of head nurses management regarding identifying patient correctly, improving effective communication, maintaining the safety of high alert medications, ensuring correct surgery procedure, reducing the risk of healthcare-associated infection, and reducing the risk of patient fall using (PDCA) model was high management level.

The present study findings in the (figure1) displayed that, the highest percentage of head nurses about less than two-thirds of them before program implementation was low management level regarding improving effective communication using (PDCA) model. Thus, from the researcher's point of view, this may be due to increased workload in the unit or lack of staff development activities to improve their knowledge and skills in the hospital. These findings are congruent with Mohamed et al., (2015), who discussed inadequate communication between caregivers with each other's because of the increased workload, so; increase in the health care workforce may improve communication. In the same line,
Paranaguá et al., (2016), who highlighted the importance of staff development activities in enhancing nurses' performance regarding patient safety.

The present study findings in the (figure 2) presented that, the highest percentage of head nurses about half of them before program implementation was low management level regarding reducing the risk of patient fall using (PDCA) model. Thus, from the researcher's point of view, this may be due to head nurses not applying assessment tools for falls, although it's available in the hospital. These present findings are in agreement with Yuswardi et al., (2015), who showed that head nurses management regarding reducing the risk from patient fall using (PDCA) model was low management level. Furthermore, the common reason head nurses management in reducing the risk of fall was at a low level due to some hospitals have not applied the assessment tool for fall.

These present findings are in disagreement with Boonyoung et al., (2013), who founded that head nurses management regarding reducing the risk of patient fall using (PDCA) model was a high management level. Furthermore, the common reason that head nurses management in reducing the risk of fall was at a high level was due to head nurses have applied assessment tool for fall and discussed that using assessment tool for fall are very useful to identify the potential risk of fall in order, to reduce fall incident in the unit.

The present study findings in the (figure 3) demonstrated that the highest percentage of head nurses about more than two-thirds of them before program implementation were moderate management level regarding applying international patient safety goals (IPSG) using (PDCA) model. Thus, from the researcher's point of view, this might be due to their role of the nursing manager in managing staff, finances, and any resources to ensure safety and quality care for patients. Also, those head nurses were obligated to provide a safe work environment. Whereas, all of them had improved after program implementation become a high management level and then slightly decreased within follow-up after 3 months.

These present findings are consistent with Seliem et al., (2019), who indicated that statistically significant improvements in all areas of practice of (PDCA) among head nurses after implementation of the intervention. While, concluded that, the implementation of a training program is successful in improving head nurses' related knowledge and practice. In the same line, Flores et al., (2013), demonstrated that the success of training staff nurses 
in PDCA as a quality improvement tool in enhancing their related competencies.

Overall, the present study findings showed that the total mean score of head nurses management regarding applying international patient safety goals using (PDCA) model had improved after program implementation become a high management level and then slightly decreased after 3 months within follow-up. Furthermore, there were highly statistical significance differences $(\mathrm{P}=<0.001)$. Thus, from the researcher's point of view, these findings assert that training program implementation is successful and effective in improving the total mean score of head nurses management regarding applying international patient safety goals using (PDCA) model.

The present study findings related to head nurses perception regarding patient's safety culture (PSC) aspects at the unit, hospital, and outcome level in (table 3) revealed that the total mean score before program implementation had potential improvement level as regards supervisor expectations promoting safety, organizational learning-continuous improvement, teamwork within units, communication openness, feedback\&communication about the error, non-punitive response to error, staffing, hospital management support for patient safety, teamwork across units, hospital handoffs \&transitions, overall perceptions of safety, and frequency of event reporting.

These present findings are in agreement with Abousallah, (2018), who showed that the total mean score before program implementation had moderate or potential improvement level of application of the patient's safety culture (PSC) aspects at the unit, hospital, and outcome level as regards supervisor expectations promoting safety, organizational learning-continuous improvement, teamwork within units, communication openness, feedback\&communication about the error, non-punitive response to error staffing, hospital management support for patient safety, teamwork across units, hospital handoffs \& transitions, overall perceptions of safety, and frequency of event reporting.

The present study findings in (figure 4) showed that the highest percentage of head nurses about more than two-thirds of them before program implementation had potential improvement level regarding patient's safety culture (PSC) aspects. Whereas most of them had improved after program implementation and follow-up after 3 months become strengths level. These findings are in agreement with Abousallah, (2018), who showed that the highest percentage of head nurses before program implementation had a potential improvement level of patient safety culture (PSC) aspects.
These findings strongly confirm with Aljabri, (2012), who explained how these variables contribute to achieving the excellent patient safety culture. These findings disagree with Hanifi et al., (2018), who showed that the surprising results the positive response rate to the patient's safety culture in some composites in the control group was reduced after the intervention although this reduction was not statistically significant. It seems that changing the patient's safety culture using educational programs requires more training courses.

In the same line, Azimi et al., (2012), who stated that the hospitals need to some educational and training programs to meet their nursing staff's needs to improve the patient safety culture. Some studies showed that significant improvements in most dimensions. Also, Abousallah, (2018), who discussed that important aspect of the patient safety culture in these hospitals need improvement, and Abu-El-Noor et al., (2019), who mentioned that a significant improvement in nurses attitudes towards most safety culture dimensions after training was observed.

Overall, the present study findings showed that the total mean score of head nurses' perception regarding patient's safety culture (PSC) aspects at the unit, hospital, and outcome level had improved after program implementation and follow-up after 3 months become strengths level. Furthermore, there were highly statistical significance differences $(\mathrm{P}=<0.001)$. Thus, from the researcher's point of view, these findings assert that training program implementation is successful and effective in improving the total mean score of head nurses' perception level regarding patient's safety culture (PSC) aspects.

As regards, the correlation between the international patient safety goals and patient safety culture in the (table 4), the present study findings founded that, there were highly statistical significance differences with a strong positive correlation between international patient safety goals (IPSG) and patient safety culture before and follow- up-program implementation and mild positive correlation after program implementation. Thus, from the researcher's point of view, these findings assert that training program implementation is successful and effective, in which there was a significant positive impact of head nurses applying international patient safety goals using (PDCA) on their patient safety culture level.

These findings are in congruence with Elmontsri, et al., (2017) \& Abousallah, (2018), who founded that a strong significant positive correlation impact of the application of international safety goals on patient's safety culture. Also, Ulrich \& Kear, (2014), who 
emphasized on the strong relation between international patient safety goals and patient safety culture, found that a better patient safety culture was associated with a lower risk of patient safety issues.

\section{Conclusions}

In light of the study findings, the following conclusion can be drawn:

It is concluded that the implementation of the training program is successful and effective in improving head nurses' management regarding applying international patient safety goals using (PDCA) model, and their perception regarding patient's safety culture (PSC) after program implementation and follow up after 3 months in all variables. Whereas, there were highly statistical significance differences $(\mathrm{P}=<0.001)$. Furthermore, there was a strong positive correlation impact of applying international patient safety goals using (PDCA) on their patient's safety culture level.

\section{Recommendations}

In light of the results of this study, the following recommendations are suggested;

1. The continuous training program and development activities about the international patient safety goals should be applied to all head and staff nurses in the study setting and should be extended to other similar settings.

2. The concept of patient safety management and the PDCA model should be included in nursing courses at the faculty of nursingAssiut University.

3. The patient safety culture perception should be measured as a continuous quality improvement (CQI) indicator for a safe health system at Rajhy Liver Hospital- Assiut University.

\section{References}

1. Abousallah, A., (2018): The Impact of Application of International Safety Goals on Patient Safety Culture: A Field Study In Private Hospitals That Working in the City Of Amman (Doctoral dissertation, Middle East University).

2. Abu-El-Noor, N., Abu-El-Noor, M., Abuowda, Y., Alfaqawi, M., \& Böttcher, B., (2019). Patient safety culture among nurses working in Palestinian governmental hospital: a pathway to a new policy. BMC health services research, 19(1), 550.

3. Aguiar, L., Guedes, M., Oliveira, R., Leitão, I., Pennafort, V., \& Barros, A., (2017): Nursing and international safety goals: hemodialysis assessment. Cogitare Enferm, 3(22).

4. Aljabri, D., (2012): Assessment of patient safety culture in Saudi hospitals: a baseline study in the eastern region. Journal of King Abdulaziz University: Medical Sciences, 98(285), 1-31.

5. Al-Rafay, S., Shafik, S., \& Fahem, S., (2018): Assessment of Nurses' Performance Regarding International Patient Safety Goals at Primary Health Care Settings. organization (eg appointment system, after-hours care arrangements, home visits), 4, 5 .

6. Ammouri, A., Tailakh, A., Muliira, J., Geethakrishnan, R., \& Al Kindi, S., (2015): Patient safety culture among nurses. International nursing review, 62(1), 102-110.

7. Azimi, L., Tabibi, S., Maleki, M., Nasiripour, A., \& Mahmoodi, M., (2012): Influence of training on patient safety culture: a nurse attitude improvement perspective. Int J Hosp Res. 2012;1(1):51-6.

8. Boonyoung, N., Yuswardi, Y., \& Thiangchanya, P., (2013): Head Nurses' management regarding patient patient safety and its related factors in public hospitals aceh Province, Indonesia (Doctoral dissertation, Prince of Songkla University).

9. Elmontsri, M., Almashrafi, A., Banarsee, R., \& Majeed, A., (2017): Status of patient safety culture in Arab countries: a systematic review. BMJ open, 7(2), e013487.

10. Flores, D., Hickenlooper, G., \& Saxton, R., (2013): An academic practice partnership: helping new registered nurses to advance quality and patient safety. OJIN: The Online Journal of Issues in Nursing, 18(3).

11. Garrett A., Drake S., \& Holcomb J., (2017): Effects of a Systematic Quality Improvement Process to Decrease Complications in Trauma Patients With Prehospital Peripheral Intravenous Access. J Trauma Nurs. Jul/Aug; 244): 236-241.

12. Gunawan, D., \& Hariyati, R., (2019): The implementation of patient safety culture in nursing practice. Enfermeria clinica, 29, 139145.

13. Hanifi, N., Yazdanshenas, Z., Namadian, M., \& Motamed, N., (2018): The Effect of Patient Safety Educational Program on Nurses' Patient Safety Culture and Patient Safety Indicators. Asian/Pacific Island Nursing Journal, 3(1), 2.

14. Johnson K., Johnson C., Porter L., \& Bryant K., (2016): Streamlining Throughput with the Implementation of a CT Coordinator. 
Radio! Manage. Jan-Feb; 38(1):13-20; quiz 21.

15. Joint Commission International, (2011): International patient safety goals: Accreditation standards for hospitals. In Joint Commission Resources.

16. Kuriakose, R., Aggarwal, A., Sohi, R., Goel, R., Rashmi, N., \& Gambhir, R., (2020): Patient safety in primary and outpatient health care. Journal of Family Medicine and Primary Care, 9(1),7.

17. Mady, H., El-Rafy, S., \& R Tantawi, H., (2017): Assessment of the Dimensional Application of International Safety Goals for Children in Hospitals. Egyptian Journal of Health Care, 8(2), 329-350.

18. Mahrous, M., (2018): Patient safety culture as a quality indicator for a safe health system: Experience from Almadinah Almunawwarah, KSA. Journal of Taibah University Medical Sciences, 13(4), 377-383.

19. Mohamed, A., Ali, M., \& Gewaifel, G., (2015): Assessment of patient safety culture in primary healthcare services in Alexandria, Egypt. Glob J Epidemiol Public Health, 2, 514.

20. Nordin, A., (2015): Patient safety culture in hospital settings: measurements, health care staff perceptions and suggestions for improvement (Doctoral dissertation, Karlstads universitet).

21. Paranaguá, T., Bezerra, A., Tobias, G., \& Ciosak, S., (2016): Support for learning in the perspective of patient safety in primary health care. Revista latino-americana de enfermagem, 24.

22. Seliem, F., Shazly, M., \& Mostafa, A., (2019): Implementation of (Plan-Do-CheckAct) Process of Quality and Measuring its Effect on Nurses' Practice of Patient Safety Goals. Egyptian Journal of Health Care, 10(3), 218-233.

23. Severinsson, E., (2013): Patient safety management in the health services: What do patients want? Journal of Nursing Management, 21, 203-205.

24. Ulrich, B., \& Kear, T., (2014): Patient safety and patient safety culture: Foundations of excellent health care delivery. Nephrology Nursing Journal, 41(5), 447-456.

25. World Health Organization, (2016): WHO patient safety assessment manual: Second
Edition, Regional Office for Eastern Mediterranean, $2^{\text {nd }}$ Cario.

26. Yuswardi, Y., Boonyoung, N., \& Thiangchanya, P., (2015): Head Nurses' Management Regarding Patient Safety in Public Hospitals Aceh Province, Indonesia. Idea Nursing Journal, 6(3), 77-82. 